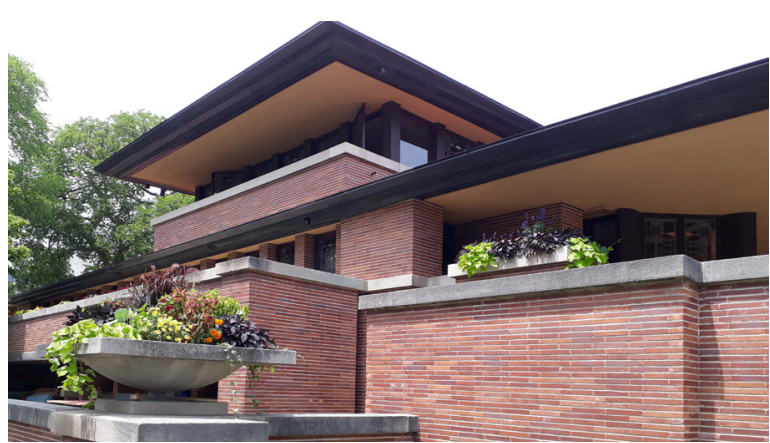

*Maria Isabel Imbronito, arquiteta e urbanista com graduação (1994), mestrado (2003) e doutorado (2008) pela FAUUSP. Docente em Arquitetura e Urbanismo na Graduação e Programa de Pós-Graduação da Universidade São Judas Tadeu.
**Marcos Mari Barreto, arquiteto e urbanista com graduação (1994) pela Universidade Católica de Santos e mestrando na Universidade São Judas Tadeu. Docente na Universidade Católica de Santos.

\section{Adolf Behne e a construção do Moderno - Parte 1}

Adolf Behne and the construction of the Modern Movement - Part 1

Maria Isabel Imbronito* e Marcos Mari Barreto**

\section{Resumo}

O livro A Construção Funcional Moderna, escrito por Adolf Behne em 1923, contém discussões fundamentais para a compreensão (e condução) da Arquitetura Moderna na década de 20. Em seu texto, o autor identifica correntes e categorias de pensamento diversas, e as explora em três tempos, determinando os três capítulos fundamentais de seu livro. O primeiro deles, objeto desse texto e tradução, tem como ênfase a recusa na adoção de princípios formais estabelecidos, e operação de retorno à finalidade para gerar um edifício vivo. O efeito desta operação reposiciona o conceito de edifício, libertando-o de uma condição estática e fachadista. Behne apoia-se nas casas de Frank Lloyd Wright dos anos 1900 para desenvolver seu argumento, e termina por escrever um texto acurado e preciso sobre a obra de Wright, apontando características que só se acentuariam na

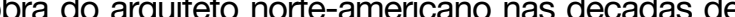
1930 e 40.

Palavras-chave: Arquitetura moderna. História da arquitetura moderna. Teoria da Arquitetura. Frank Lloyd Wright. A construção funcional moderna.
Abstract

The book Der moderne Zweckbau, written by AdoIf Behne in 1923, reveals fundamental discussions for the understanding (and conduction) of Modern Architecture in the 1920s. In this book, the author identifies three courses or categories of thoughts, and explores them to compose the three fundamental chapters of the book. The first chapter, which is the object of this paper and, in part, translated, emphasizes the denial of established forma principles, and highlights the return to purpose and function to generate a living architecture. The effect of this operation resets the concept of building, freeing it from a static and prescribed condition. Behne relies on Frank Lloyd Wright's houses from the 1900s to develop his argument, and ends up writing an accurate text about Wright's design procedures, pointing to features that would only get accentuated in the work of the American's architect during the 1930s and 40s.

Keywords: Modern Architecture. Modern Architecture History. Architectural Theory. Frank Lloyd Wright. The Modern Functional Building. 
1. A lista de obras publicadas de Adolf Behne presente em Esquide (1994) inclui textos nas revistas Frühlich (de Taut), Das Neue Frankfurt, Die Form, Wasmuths Monatshefte fur Baukunst, Die Weltbühne, Sozialistische Monatshefte, entre outras. Ainda segundo Banham (1979, p.284), citações de Behne foram incluídas na revista De Stijl no início da década de 1920

2. Segundo Frampton (2008, p.140, 141), Behne, juntamente com Gropius e Taut, fundou o Arbeitsrat für Kunst, que acabou por fundir-se com o Novembergruppe.
0

livro A Construção Funcional Moderna (Der Moderne Zweckbau), escrito em 1923, posiciona Adolf Behne como um importante teórico alemão do início da década de 1920. Escrevendo ao mesmo tempo em que se construíam as ideias e as obras modernas, e antecipando, com sua escrita ensaística, os desdobramentos radicais das correntes que identifica, Behne interpreta com nitidez as relações entre movimentos complementares e contrários, e elabora uma narrativa de base histórica na qual arquitetos e obras se sucedem e se articulam, construindo uma direção para seu livro e para a própria arquitetura moderna. Isso porque, conforme aponta Esquide, autor do prefácio da edição espanhola de A Construção Funcional Moderna, o livro de Behne, ao tratar da produção de seu tempo, foi também, em alguma medida, responsável pelas formulações e rumos tomados posteriormente pela arquitetura moderna.
Así puede afirmarse que Behne sigue, prevé, impulsa y encauza uma parte sustancial de la nueva arquitectura que tendrá lugar a partir de 1923, (...), que resultará diferente y cabalmente explicable a partir de las argumentaciones y de la existencia previa de Der Moderne Zweckbau (ESQUIDE, 1994, p.10).

Antes desse livro, Behne já havia escrito sobre arte e arquitetura moderna, atuando junto a revistas $^{1}$ e movimentos de vanguarda ${ }^{2}$. Depois de $\mathbf{A}$ Construção Funcional Moderna, contudo, seus textos sobre arquitetura moderna ficaram restritos aos poucos anos que antecederam a 1930. De 1930 até o final da Segunda Guerra Mundial, a estratégia de Behne foi dedicar-se ao estudo da arquitetura do passado e, sob a neutralidade do tema, evitar o enfrentamento com o regime nazista (ESQUIDE, 1994, p.8 e 9). Em 1945, Behne retomou alguns escritos sobre artistas modernos emigrados. Tendo falecido em 1948, e devido ao desvio temático durante os anos de turbulência, 
3. Alan Colquhoun (2005) cita Behne em dois momentos no livro La arquitectura moderna: una historia desapasionada (publicação original de 2002): ao falar do Expressionismo Alemão (2005, p.89, 90) e ao falar da Alemanha de Weimar (2005, p.159, 160).

4. Behne é citado no capítulo sobre Expressionismo Alemão no livro de Kenneth Frampton, Historia crítica da arquitetura moderna, cuja publicação original data de 1980. O volume consultado é $2^{\mathrm{a}}$ Edição da Martins Fontes, 2008.

5. Para o autor, o funcionalismo está associado a desenhos peculiares de edifícios concebidos para o atendimento pormenorizado das funções; o racionalismo prevê a adoção de princípios de organização (sistemas) e princípios formais extensíveis a situações abrangentes; e o utilitarismo responde apenas a questões imediatas e oportunistas no que compete à eficácia e custo dos edifícios. O assunto será aprofundado nos próximos textos a serem elaborados sobre o autor, em especial Adolf Behne e a construção do moderno - parte 3 .

6. Em alemão, o termo adotado é Haus, que correspon- de a "casa", e representa o ponto culminante do capítulo tratado: as Casas da Pradaria do arquiteto americano Frank Lloyd Wright. Behne não adota a palavra "Pradaria" mas, em algum momento, utiliza o termo Landhaus (a casa no terreno) para referir-se a essas casas. Segundo nosso entendimento, é importante considerar, nas Casas da Pradaria, a condição isolada do edifício no terreno para sua plena constituição volumétrica, construtiva e funcional, razão pela qual optamos por adotar a tradução "edifício", conforme a versão espanhola de Josep Giner i Olcina Contudo, ao adotarmos a tradução "edifício", soma-se um conjunto de significados que acompanham o termo em português: uma "obra arquitetônica" (casa, prédio, igrejas, ginásios) que atende às necessidades humanas e que tem uma importância figurativamente, qualquer obra executada com arte; um projeto mental que demandou empenho (Dicionário Houaiss da Língua Portuguesa, consultado à página 1099 da edição de 2001). Todas essas nuances vem enriquecer o termo empregado.

7. Em alemão, o termo adotado é Raum, que corresponde a "quarto". A tradução espanhola de Josep
A Construção Funcional Moderna tornou-se o mais impactante registro de seu pensamento.

Citado por Colquhoun ${ }^{3}$, Frampton 4 , entre outros, a retomada deste autor nos parece oportuna não apenas pela construção do panorama histórico e do pensamento arquitetônico do período entre 1890 e 1920 que ele oferece em seu livro mas, sobretudo, pelo entendimento que fornece dos conceitos de funcionalismo, racionalismo e utilitarismo. A compreensão destes termos através da formulação complexa de Behne fundamenta toda e qualquer leitura que se possa fazer sobre obras e autores modernos ${ }^{5}$.

O livro de Behne é, em si, uma obra inventiva e coesa. Das obras arquitetônicas pontualmente inseridas e articuladas, Behne extrai e discute modelos de pensamento. A sucessão destes modelos estrutura-se em saltos qualitativos, apresentados em sequência nos três capítulos de seu livro: Não mais fachada, mas edifíció; Não mais edifício, mas quarto conformado ${ }^{7}$; Não mais quarto conformado, mas realidade configurada. $\mathrm{O}$ autor parte assim do mais estanque e desvinculado elemento, a fachada isolada, até a concepção abrangente, dinâmica e coletiva de cidade, discutindo neste percurso o indivíduo e a sociedade, a expressão e a abstração, o estático e o movimento, o funcionalismo especializado e o funcionalismo flexível. Apesar de estabelecer uma narrativa crescente ao longo do livro e de considerar os desdobramentos negativos de cada uma das diferentes abordagens que identifica, Behne permite-se adentrar na lógica constitutiva e argumentativa dos artistas, períodos e correntes, valorando a cada um e posicionando-o em relação aos demais, enquanto parte constituinte de um panorama maior.

Paralelamente aos saltos qualitativos com que Behne organiza seu livro, há um argumento principal que permeia sua narrativa: o contraponto entre $\mathrm{o}$ atendimento à finalidade e o estabelecimento do "jogo" formal, binômio presente no campo da arquitetura, segundo o autor, desde os primórdios. Para Behne, a ênfase dada a cada um desses dois aspectos (finalidade e forma) por correntes diferentes (funcionalismo e racionalismo) determina, no nível do objeto arquitetônico isolado, a dimensão relativa do primeiro (em diálogo com a finalidade) e a dimensão absoluta do segundo (com ênfase na forma). Quando o objeto arquitetônico passa a ser articulado em conjunto com os demais elementos urbanos, na escala da cidade, ocorre o oposto: o efeito disjuntivo do primeiro (enquanto objeto individual e único que concorre com a ideia de conjunto) e a estratégia configurativa do segundo (enquanto objeto típico submetido a um princípio geral, que se mostra capaz de articular-se num todo integrado).

Este nosso trabalho, que parte da leitura de $\mathbf{A}$ Construção Funcional Moderna, faz uma revisão sistemática das colocações de Behne, que são apresentadas em divisões idênticas às do 
autor, de modo não só a propiciar seu entendimento, mas a ressaltar as diferenças qualitativas que Behne propõe.

Assim, os três capítulos do livro A Construção Funcional Moderna darão origem a três artigos distintos e independentes, organizados em sequência. Para cada artigo elaborado é feita uma discussão alinhada ao texto de Behne, acompanhada pela tradução de trechos de A Construção Funcional Moderna que foram considerados por nós como aqueles representativos dentro de cada capítulo.

\section{A polaridade entre finalidade e jogo presente na introdução do livro A Construção Funcional Moderna}

No início de seu texto, Behne introduz a diferença opositiva entre finalidade e jogo, antecipando a tônica da questão tratada ao longo de seu livro. Para o autor, a discussão presente na virada para o século XX propõe-se a recuperar um equilíbrio entre os aspectos utilitários e estéticos, depois de longo período de primazia da forma, que foi perpetrada através de leis gerais que "se transformaram em princípios, mais firmes, permanentes e rígidos do que a satisfação da função instrumental” (BEHNE, 1994, p. 21).
Após introduzir a dualidade no atendimento entre finalidade e forma na arquitetura ao longo do tempo, Behne detém-se no período de transição e dissolução do pensamento formal até então dominante. Para o autor, em 1890, a arte se equiparava ao ornamento: chega-se à forma desejável "apesar da finalidade" (BEHNE, 1994, p. 22). Já em 1900, desenvolve-se um "olhar receptivo à beleza do útil” (BEHNE, 1994, p. 22): nega-se a aceitar o belo como supérfluo e desenvolve-se uma disposição estética oriunda da lógica do funcional. Percebe-se que a construção utilitária, ao não se submeter a um jogo formal preestabelecido, tampouco "é deficiente do ponto de vista estético" (BEHNE, 1994, p.22): conjura-se, no lugar de um princípio estético formal, que a conformação arquitetônica resultante do atendimento à finalidade adquire um valor estético que é plenamente compatível com a existência humana.

Tem início um momento de valorização da obra de arte respaldada na engenharia e na lógica prática: pontes metálicas, gruas, grandes galpões. Despontam outros modos novos de conceber, perceber e valorar a obra arquitetônica. "As construções são consideradas cada vez mais como instrumentos." (BEHNE, 1994, p.23).
7. (cont.) Giner i Olcina adota
o termo Espacio conforma-

do, que nos parece adequada. A ideia geral do capítulo em questão consiste na plena e peculiar adequação e conformação de cada ambiente construído à sua finalidade, e a analogia ao organismo é muito presente. 
Capítulo 1: A casa solta: não mais fachada, melhor edifício!

Após contrapor finalidade e jogo, Behne reage à predominância das leis formais ideais que dominaram o princípio da construção por longo período. A fachada, "seco academicismo", é o elemento estanque que representa esse tipo de pensamento: entendida enquanto mero rebatimento compositivo, tornou-se o aspecto preponderante na solução do edifício. Os procedimentos gerais recorriam a questões de ordem compositiva, em detrimento a prerrogativas construtivas ou programáticas. Behne identifica, na virada do século XX, um movimento de retorno à finalidade para trazer "efeitos renovadores" para a arquitetura. Estes movimentos defendem o descarte de ataduras formais para "engendrar, a partir do conhecimento profundo da função e adotando-se uma posição neutra [com relação à aplicação de um princípio formal apriorístico], uma forma vivente, rejuvenescida e intensa." (BEHNE, 1994, p.21).

Behne reconstitui a linha de pensamento pela valorização do processo de projeto com base na finalidade desde 1895, fundamentada no tripé Otto Wagner (Áustria, 1841-1918), Berlage (Holanda, 1856-1934) e Alfred Messel (Alemanha, 1853-1909), e analisa alguns pronunciamentos e obras desses arquitetos. Os três defendem o atendimento à finalidade e aos novos programas para proporcionar construções econômicas e ágeis, cuja forma deve evoluir da compreensão objetiva das exigências do edifício (Figura 1).

\section{H. P. Berlage}

Grundlagen und Entwicklung der Architektur, 1908

1. Princípio geométrico;

2. Não aderir a estilos;

3. As formas devem evoluir em direção ao "objetivo".

\section{O. Wagner}

Die Baukunst unserer Zeit, 1895

1. Compreensão escrupulosamente exata e satisfação completa da finalidade;

2. Eleição acertada dos materiais de execução (disponíveis, manejáveis, econômicos e duráveis);

3. Construção econômica e fácil;

4. A forma resulta destas premissas.

Figura 1. Pontos defendidos por Berlage e Otto Wagner, citados por Adolf Behne.

Ao refletir sobre o aporte teórico da década de 1900 e sobre as obras construídas destes três arquitetos, Behne conclui que, para Berlage, Otto Wagner e Alfred Messel, a exigência para a objetividade manifesta-se mais como um "combate contra a ausência de objetividade" do que, propriamente, como soluções arquitetônicas radicalmente transformadas a ponto de se desprenderem do passado de modo inovador. Irá identificar 
só na obra arquitetônica de Frank Lloyd Wright (Estados Unidos, 1867-1959), o ponto de inflexão na tomada da finalidade para engendrar um tipo novo de edifício. Com Wright, é a casa ${ }^{8}$ - até então pouco associada a uma construção objetiva ou utilitária se comparada ao galpão industrial que deflagra o espaço funcional com implicações formais livres e experimentais. A partir das casas isoladas feitas por Wright entre 1890 e 1910, que foram divulgadas na Alemanha em 1910-11 por ocasião da publicação do portfólio Wasmuth (WRIGHT, 1910), Behne descreve com precisão tanto as características da obra de Wright que se acentuariam em sua fase usoniana (das décadas de 1930 e 40), como as repercussões que as tais Casas da Pradaria das décadas de 1900-1910 tiveram na Alemanha, Holanda, Suíça e Checoslováquia.

Interessa para Behne ressaltar, na obra de Wright, a operação que substitui a fachada estática pelo desenvolvimento dinâmico da planta, e nota como "as exigências de comodidade rompem a cadeia de compartimentos do esquema ornamental e exploram o livre equilíbrio do espaço" (BEHNE, 1994, p.34). Nestas plantas "descompartimentadas", Behne chama a atenção para a continuidade dos poucos elementos murais que "indicam e acompanham concisamente a comunicação mais cômoda entre os espaços" e dão "movimento a um espaço surpreendente e particular" (Id., 1994, p.33). A casa passa a ser uma "organização de espaços equilibrados livremen- te" (Id., 1994, p.33). Os espaços em continuidade respondem às finalidades e a planta desenvolve-se a um ponto em que "cada peça de mobiliário tem seu lugar” (BEHNE, 1994, p.33).

A isso se aliam "coberturas extraordinariamente planas com balanços" (BEHNE, 1994, p.33). Behne prossegue a análise para desvendar a articulação volumétrica que "prescinde do ornamental":

a organização estética da casa é resultado de uns poucos elementos básicos: um ativo movimento horizontal, a detenção a ele imposta por algumas verticais inteligentes e bem marcadas, e umas poucas superfícies murais...", resultando na "relação precisa de elementos abertos e fechados. (BEHNE, 1994, p.35).

A leitura de Behne sobre as casas de Frank Lloyd Wright pode ser bem exemplificada através das casas que compuseram o Portfolio Wasmuth (WRIGHT, 1910): Heller, Heurtley (1902), Hardley, Hickok, Willits (1901), Fricke (1901-02) (Figura 2), Dana (1902-04), W. E. Martin (1903) (Figura 3), Cheney (1903) (Figura 4), D. Martin (1903-05), Coonley (1907), Robie (1908-10) (Figura 5), entre outras. Para Behne, é com Wright que a finalidade toma a frente e assume papel preponderante da condução do processo de conceber a arquitetura. Ao descartar formas estilísticas e aplicar um raciocínio integral ao volume, a fachada como elemento de frontalidade não terá mais nenhum valor. Por este motivo, reconhece: "Não mais fachada, mas edifício!" 


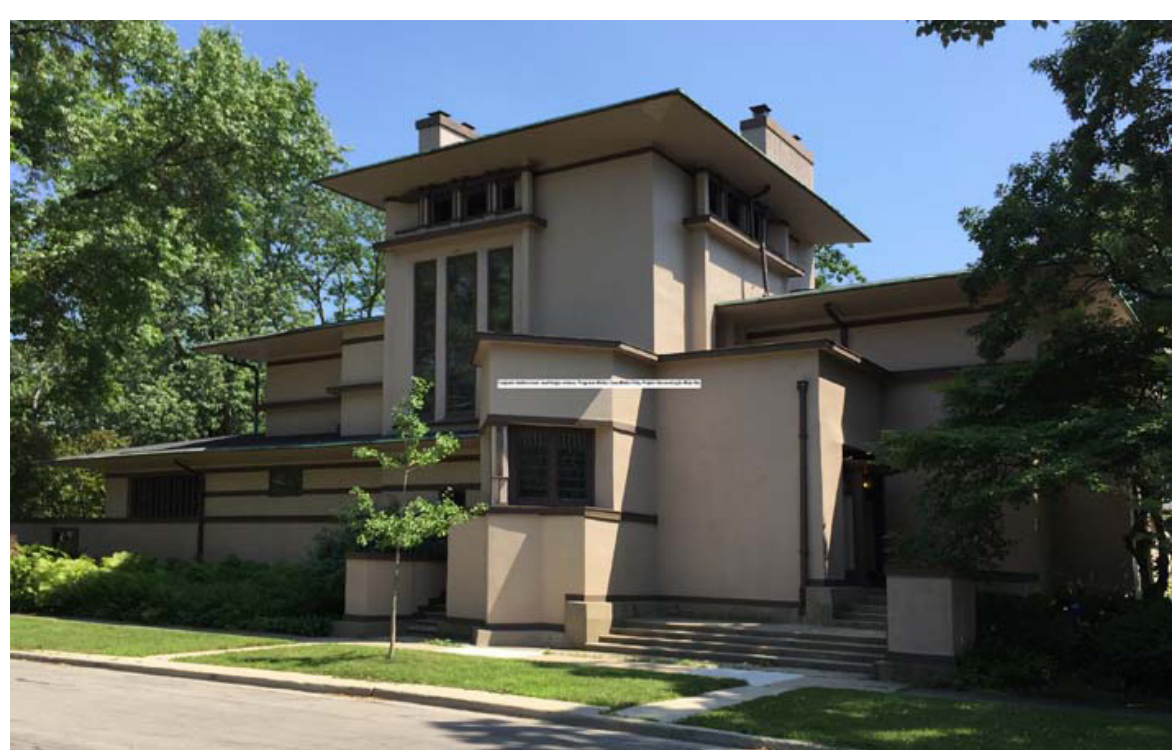

Figura 2. Frank Lloyd Wright. Casa Emma Martin (antiga Casa W. G. Fricke), 1901-02, Oak Park. Fonte: Foto Rodrigo Queiroz.

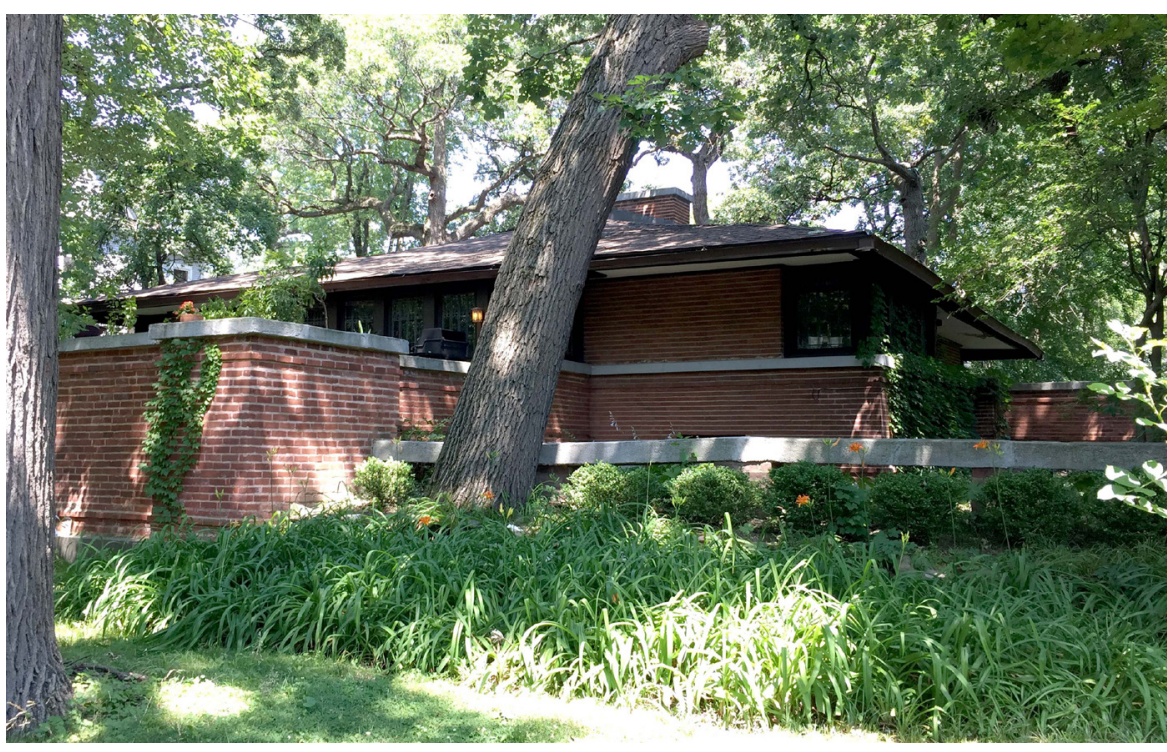

Figura 4. Frank Lloyd Wright. Casa E. H. Cheney, 1903, Oak Park. Fonte: Foto Rodrigo Queiroz

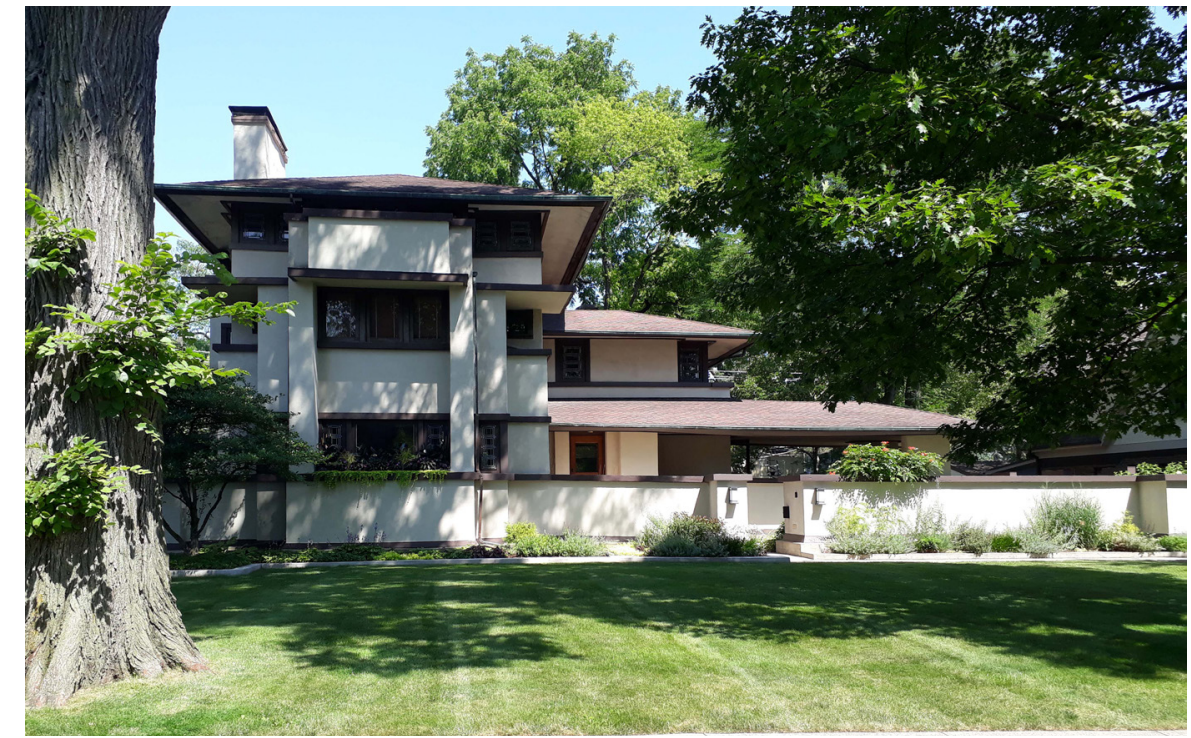

Figura 3. Frank Lloyd Wright. Casa William E. Martin, 1903, Oak Park. Fonte: Foto Rodrigo Queiroz.

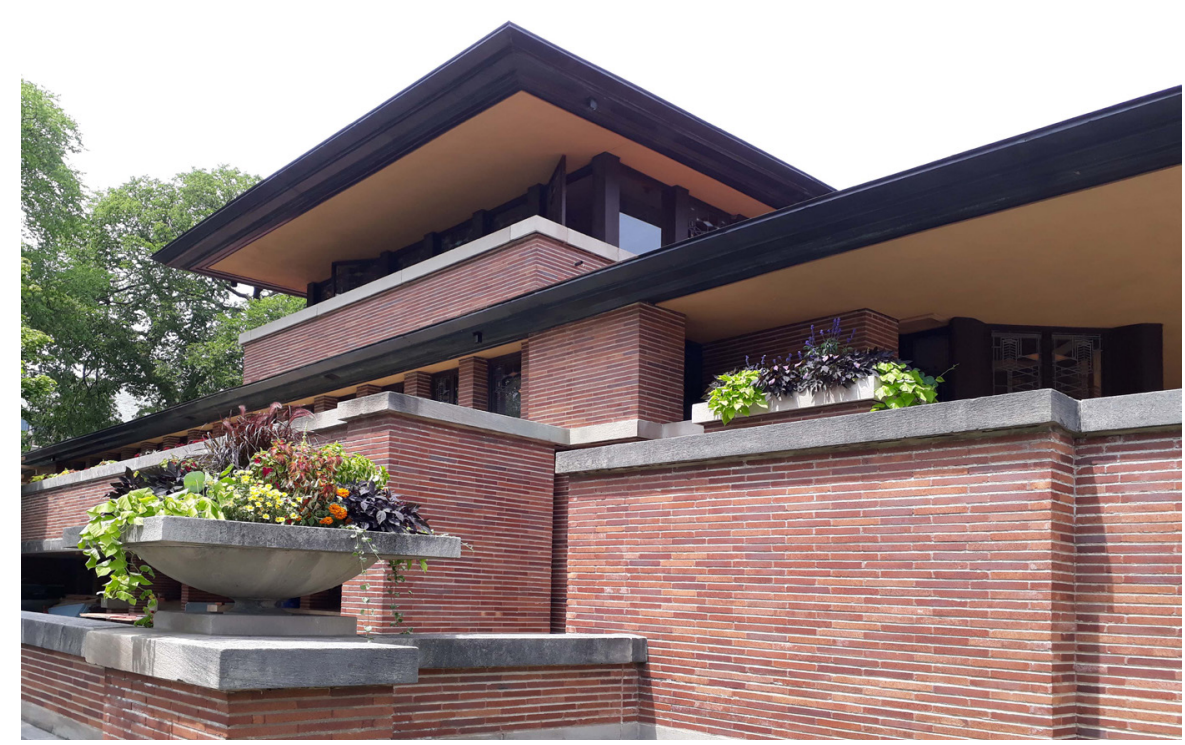

Figura 5. Frank Lloyd Wright. Casa Robie, 1908-10. Hyde Park. Fonte: Foto Maria Isabel Imbronito 


\section{Texto no idioma original (alemão)}

\section{Nicht mehr Fassade / sondern Haus}

In die Mitte der neunziger Jahre fällt auch die Entwicklung des modernen Landhaus-Grundrisses durch Frank Lloyd Wright - Chicago, den Schüler Sullivans. Nach der üblichen Terminologie fällt das Landhaus nicht in die Kategorie der Zweckbauten. Dennoch ist die Gesinnung, wie sie aus Wrights neuen Grundrissen spricht, für uns außerordentlich wichtig, da sie charakterisiert werden muß als die Befreiung des Grundrisses aus formalistischer Starre durch die Zurückführung auf das funktionelle Element. Die Entwicklung beginnt etwa zwischen den beiden Grundrissen Winslow - River Forest (1893) und Heller- Chicago (1896) und erreicht ihre Höhe in dem Grundriß Coonley - Riverside (1908). Hier ist aus der sorgfältigsten Erfassung aller Ansprüche auf Bequemlichkeit, Ruhe, Übersichtlichkeit die Zusammenschachtelung der Räume in ein ornamentales Schema durchbrochen zugunsten einer "freien Balancierung im Raum" (Herre). Keine Spur mehr von Symmetrie oder von Achse, sondern Mauern, die knapp den bequemsten Verkehrsweg aller Räume markieren und begleiten. Die Anpassung an die Lebenfunktionen geht so weit, daß jedes Möbel im Grundriß seinen Platz hat. Dieser Grundriß „entfaltet sich”. Das Haus kompliziert sich nicht mit Treppen in die Höhe - ein Rudiment mittelalterlicher Burgturm und Mauerwall-Architektur - , das Land bietet ja Raum, um das Haus mit fast allen seinen Zimmern unmittelbar auf der Erde sich entwickeln zu lassen.
Wrights Grundrisse schachteln nicht Räume zusammen, sondern bewegen Raum - so asymmetrisch, wie das Leben merkwürdigerweise selbst ist. Wright kam bereits - unter japanischem Einfluß - zu außerordentlich flachen und meist weit vorgezogenen Dächern. Das bedeutet: Unterdrückung des Malerischen, Betonung des Konstruktiven und Kubischen. Das Haus als Organisation frei ausbalancierter Räume wirft konsequent das Dach als einen Hut, der alles zusammenbringt, ab. Auch das Dach wird aus einem "Motiv" zu einer "Funktion".

Die Einwirkungen Wrights auf die europäische Baukunst waren bedeutend: auf Deutschland (Peter Behrens, Gropius, Mendelsohn, Mies van der Rohe); auf Holland (Oud [geb. 1890], Jan Wils, van t'Hoff, Greve); auf die Schweiz (Le Corbusier); auf Tschechien (Obrtel, Krejcar, Tyl, Cerny, Visek, Fragner, Feuerstein) - zunächst wohl mehr der Aufriß als der Grundriß, der erst neuerdings volles Verständnis findet.

Im Aufbau sind Wrights Landhäuser von größter Bedeutung durch die konsequente Betonung der Horizontale, deren weit gespannte nervige Kraft - stets in klügster Kontrastierung mit knappen Vertikalen - die Häuser geradezu als Bestandteile der Straße erscheinen läßt, obwohl sie fast nie ihren Eingang offen zur Chaussee stellen, in einer sehr eigenartigen Durchdringung von 
Öffentlichkeit und Intimität. Unter Verzicht auf alle Ornamentik, die nur im Innern eine unseren Geschmeck manchmal verblüffende Rolle spielt (neuerdings zunehmend auch am Außenbau), ergibt sich der ästhetische Aufbau des Hauses aus den Grundelementen beschleunigter Horizontalbewegung, klug und markant stoppen der Vertikalen und weniger glatter Mauerflächen, die aber niemals als tragende, immer als getragene Teile erscheinen. Alle sichtbaren Teile wirken durchaus als Funktion: das präzise Verhältnis der offenen und geschlossenen Teile ergibt das "Haus".

Jeder aufmerksame Betrachter empfindet die nähe, in der Geschichte der Baukunst völlig neue Verbindung mit maschinellen Schönheitswerten. In einem Aufsatze, den Wright 1908 im "Architectural Record", New York geschrieben hat, heißt es: "Die Maschine ist nicht mehr aus der Welt zu schaffen, sie bleibt und ist der Pionier der Demokratie, die unserer Hoffnungen und Wünsche letztes Ziel ist. Der Architekt unserer Zeit sollte keine wichtigere Aufgabe kennen als die Verwendung dieses modernen Werkzeuges, soweit es überhaupt möglich ist. Was tut er aber statt dessen? Er mißbraucht dieses Werkzeug zur Erzeugung von Formen, die entstanden sind in anderen Zeiten, unter einem fernen Himmel, Formen, die heute ertötend wirken, weil man ihnen nirgends entgeht, und das alles geschieht mit Hilfe der Maschine, deren Hauptaufgabe es ist, gerade diese Formen zu zerstören".
Berlage, Otto Wagner und Alfred Messel (dieser mit den oben gegebenen Einschränkungen) hatten die Forderung der Sachlichkeit siegreich verfochten. In der Hauptsache freilich beschränkte sich ihre Sachlichkeit auf eine Bekämpfung und Vermeidung der Unsachlichkeit. Der gesunde Menschenverstand, Gefühl für Reinlichkeit und die Praxis setzten(setzen) sich durch, die Scheu vor dem Zweck hörte auf. Aber ganz unmittelbar dicht an die Aufgabe kamen auch sie noch nicht heran. Sie blieben Häuserbauer. Ihre Aufgaben (Börse, Verwaltungsgebäude usw.) mochten dabei eine Rolle spielen. An den Grundriß gingen sie jedenfalls nicht in einem neuen Sinne heran. Selbst ein Otto Wagner betont ausdrücklich die Wichtigkeit der Symmetrie im Grundriß: "Eine einfache, klare Grundrißdisposition bedingt meist die Symmetrie des Werkes. Es liegt etwas Abgeschlossenes, Vollendetes, Abgewogenes, nicht Vergrößerungsfähiges, ja Selbstbewußtes in einer symmetrischen Anlage, auch Ernst und Würde, die steten Begleiterinnen der Baukunst, verlangen sie".

Einen entscheidenden Vorstoß brachte erst Wright, dessen positive Sachlichkeit den Landhaus-Grundriß durch das Zurückgehen auf die elementarsten Funktionen der Wohnenden völlig neu und unmittelbar aus dem Leben entwickelte. Hier ist die entscheidende Wendung von formaler Gebundenheit zu einer Hingabe an das Leben selbst - in dem Vertrauen, daß die einem gesunden 
und beherrschten Leben entsprechende Gestalt notwendig schön sein wird - eine neue Eroberung des Raumes vom Zwecke, von der Funktion aus.

Diese Gesinnung, auf große und für die Zeit typische Aufgaben angewendet, könnte auf eine neue Baukunst hinleiten. Als solche Aufgaben stellten sich in dem ersten Jahrzehnt des Jahrhunderts in steigendem Maße Fabrikbauten, industrielle Probleme dar.

Die akademisch-historischen Stilformen sind abgeworfen, der Begriff der Fassade erledigt. Noch stehen geblieben ist das "Haus". Die Erfolge sind erzielt durch das Zurückgehen auf den Zweck - in einer baugeschichtlichen Entwicklung, die ihr genaues Gegenstück hat in der Malerei der Zeit, welche gleichfalls die akademisch-historischen Stilformen beseitigte. Ihr Mittel ist der Naturalismus, der stets in der Entwicklung der Malerei den Sinn hat, eine neue Vorurteilslosigkeit zu ermöglichen - ganz analog der Bedeutung, die das Zurückgehen auf den Zweck für das Bauen hat. "Der Naturalismus in der Baukunst ist die Zweckmäßigkeit" (Karl Scheffler: Messel, S. 14).

\section{Tradução ao português}

8. Landhaus-Grundrisses: a ser entendida como a casa no campo de planta no chão, que substituímos por casa da pradaria.

\section{Não mais fachada, mas edifício}

Na metade dos anos 1890, ocorreu o desenvolvimento da planta da moderna casa da prada- ria ${ }^{9}$, com Frank Lloyd Wright - de Chicago, aluno de Sullivan. Pela terminologia usual, casas não se enquadrariam na categoria de edifícios funcionais. No entanto, a mentalidade expressa na nova planta de Wright, de extrema importância para nós, deve ser caracterizada como a libertação da planta contra toda a rigidez formalista, mediante o retorno aos elementos funcionais. A evolução começa em algum momento entre as plantas Winslow - River Forest (1893) e Heller - Chicago (1896), e atinge o seu ápice na casa Coonley - Riverside (1908). Aqui ocorre a mais cuidadosa apreensão de todas as reivindicações de comodidade, tranquilidade e claridade na disposição dos ambientes, com o rompimento do rígido encaixe dos espaços do esquema ornamental em favor de um "livre equilíbrio do espaço". Não há mais vestígio de simetria ou de eixo central, mas a presença de muros, que indicam e acompanham a ligação mais conveniente entre os ambientes. A adaptação às funções da vida vai tão longe que cada peça de mobiliário tem seu lugar em planta. Essa planta "se desenvolve". A casa não se complica em escadas e alturas - rudimento medieval da torre do castelo e da arquitetura intramuros -, o terreno oferece espaço suficiente, e a casa pode se desenvolver com quase todos os quartos diretamente sobre o chão.

As plantas de Wright não enrijecem os espaços, mas dão movimento a um espaço tão assimétrico e surpreendente quanto a própria vida. Wright 
chegou - por influência japonesa - a coberturas extraordinariamente planas com avançados beirais. Isso implicou na supressão do pitoresco e na ênfase para o construtivo e o cúbico. Em consequência, a casa enquanto uma livre organização de espaços em equilíbrio promoveu a cobertura a um abrigo que reúne tudo. Assim, a cobertura passou de "motivo" a "função".

A influência de Wright para a arquitetura europeia foi significativa: na Alemanha (Peter Behrens, Gropius, Mendelsohn e Mies van der Rohe); na Holanda (Oud [nascido em 1890], Jan Wils, van t'Hoff, Greve); na Suíça (Le Corbusier); na República Tcheca (Obrtel, Krejcar, Tyl, Cerny, Visek, Fragner, Feuerstein) - a princípio, priorizando a elevação frente à planta que, só recentemente, foi plenamente compreendida.

O mais importante na estruturação das casas unifamiliares isoladas de Wright foi a ênfase consistente dada à horizontal, cuja potência, tensa e alongada - sempre no inteligente contraste com curtos elementos verticais - vincula a casa como simples elemento da rua e, embora quase nunca disponha de uma entrada diretamente para a via, estabelece uma peculiar integração entre o público e o privado. Ao renunciar à ornamentação, que ainda desempenha algum papel - intrigante, para nosso gosto - no interior da casa (mas também no exterior), o resultado estético da construção resulta de uns poucos elementos básicos, provenientes do acentuado movimento horizontal, a detenção imposta por verticais inteligentes e marcadas, e por superfícies murais consistentes, que não se comportam como elementos portantes, mas portados. Todos os elementos visíveis operam inteiramente sob essa função: a casa resulta da relação precisa entre as partes abertas e fechadas.

Qualquer observador atento percebe aqui uma proximidade, inteiramente nova na história da arquitetura, em conexão com valores da beleza maquinista. Em um ensaio publicado por Wright em 1908 na "Architectural Record", de Nova York, este afirma: "A máquina já não pode ser eliminada do mundo, ela permanecerá e é pioneira da democracia, que é nosso objetivo e aspiração final. $O$ arquiteto de nosso tempo não deveria atribuir-se nenhuma tarefa mais importante do que o uso dessa ferramenta moderna. $O$ que ele faz, em vez disso? Ele abusa dessa ferramenta para recriar formas surgidas em outros tempos, sob um céu distante, formas que, hoje, são mortíferas e desnecessárias em qualquer lugar, e o faz com a ajuda da máquina, cuja principal tarefa seria, justamente, destruir essas formas."

Berlage, Otto Wagner e Alfred Messel (com as limitações descritas anteriormente) defenderam com êxito a exigência pela objetividade. Mas sua defesa limitou-se, principalmente, a um combate contra a impropriedade e à ausência de objetividade. Contudo, no senso comum, o sentimento pela pureza e a prática prevaleceram, e a timidez dade Estadual de Campinas - UNICAMP. 
frente ao propósito e à finalidade terminou. Mas eles não atingiram seu objetivo. Eles seguiram sendo construtores de edifícios. Suas funções (bolsa de valores, edifícios administrativos, etc.) deveriam ter desempenhado um papel. De qualquer forma, a planta não foi abordada com um novo sentido. Mesmo Otto Wagner enfatiza expressamente a importância da simetria da planta: "Uma disposição simples e clara da planta geralmente requer a simetria da obra. Em uma planta simétrica, há algo consumado, acabado, intocável, autoconsciente; a seriedade e a dignidade, companheiras constantes da arquitetura, a exigem."

Um primeiro impulso decisivo foi dado por Wright, e uma objetividade positiva se desenvolveu no plano da casa, através do retorno às funções elementares do habitar, completamente renovadas e imediatamente extraídas a partir da vida. Aqui está a passagem decisiva da atadura formal para a devoção à própria vida - na confiança de que a vida prevalecida e saudável será necessariamente bela - e a conquista do novo espaço conduzida pelo propósito e pela função.

Essa atitude, aplicada aos grandes programas típicos desse período, poderia levar a uma nova arte de construir. Com tais programas, levantou-se, na primeira década do século, uma quantidade cada vez maior de edifícios de fábricas, com uma lógica industrial inerente.
As formas acadêmico-historicistas foram descartadas, o termo fachada se extinguiu. Permaneceu o "edifício". As realizações foram alcançadas através do retorno à finalidade - em um desenvolvimento da história da arquitetura que tem sua contraparte exata na pintura da época, que também elimina as formas acadêmico-historicistas. Retornou-se ao naturalismo que sempre representou, no desenvolvimento da pintura, parâmetros para permitir novas atitudes - bastante análogo ao significado que teve o retorno à finalidade na arquitetura: "O naturalismo, na arte de construir, corresponde à finalidade." (Karl Scheffler: Messel, p.14).

\section{Referências}

BANHAM, Reyner. Teoria e projeto na primeira era da máquina. São Paulo: Perspectiva, 1979.

BEHNE, Adolf. 1923. La construcción funcional moderna. Edição e prefácio de José Ángel Sans Esquide. Tradução de Josep Giner i Olcina. BarceIona: Colegio de Arquitectos de Cataluña y Ediciones Serbal, 1994.

\section{Der Moderne Zweckbau. Berlin:}

Gebr.Mann Verlag, sd.

COLQUHOUN. Alan. La arquitectura moderna.

Una historia desapasionada. Barcelona: Gustavo Gili, 2005. 
ESQUIDE, José Ángel Sanz. Prefacio. In: BEHNE, Adolf. 1923. La construcción funcional moderna. Edição e prefácio de José Ángel Sans Esquide. Tradução de Josep Giner i Olcina. Barcelona: Colegio de Arquitectos de Cataluña y Ediciones Serbal, 1994, p. 7-12.

FRAMPTON, Kenneth. História crítica da arquitetura moderna. São Paulo: Martins Fontes, 2008.
WRIGHT, Frank Lloyd. Frank Lloyd Wright Wasmuth Portfolio. Volumes 1, 2. Berlin: Ernst Wasmuth, 1910. Disponível em: https://collections. lib.utah.edu/search?q=wasmuth\&sq=\&fd=title_t\% 2Cdate_t\%2Csetname_s\%2Ctype_t\&rows=25\&s ort=\&page $=1$ \&gallery=0\&year_start=\&year_end $=$. Acesso 02/03/2019,

ZEVI, Bruno. Frank Lloyd Wright. Barcelona: Gustavo Gili, 1998. 